\title{
Anticoagulants: A Review of the Pharmacology, Dosing, and Complications
}

\author{
Mohammed Alquwaizani • Leo Buckley • \\ Christopher Adams · John Fanikos
}

Published online: 21 April 2013

(C) The Author(s) 2013. This article is published with open access at Springerlink.com

\begin{abstract}
Anticoagulants remain the primary strategy for the prevention and treatment of thrombosis. Unfractionated heparin, low molecular weight heparin, fondaparinux, and warfarin have been studied and employed extensively with direct thrombin inhibitors typically reserved for patients with complications or those requiring intervention. Novel oral anticoagulants have emerged from clinical development and are expected to replace older agents with their ease of use and more favorable pharmacodynamic profiles. Hemorrhage is the main concerning adverse event with all anticoagulants. With their ubiquitous use, it becomes important for clinicians to have a sound understanding of anticoagulant pharmacology, dosing, and toxicity.
\end{abstract}

Keywords Thrombosis - Coagulation - Anticoagulants · Unfractionated heparin - Low molecular weight heparins . Direct thrombin inhibitors - Warfarin · Dabigatran ·

Rivaroxaban · Apixaban

\section{Introduction}

Anticoagulants are the cornerstone therapy for thrombosis prevention and treatment. While anticoagulants are commonly employed, their use is often associated with adverse drug events and increased readmission rates. In older patients presenting to an Emergency Department with a warfarin adverse drug event, about half required hospitalization [1]. Despite novel anticoagulants being touted as replacements for warfarin and heparin products, rivaroxaban has been

M. Alquwaizani · L. Buckley · C. Adams · J. Fanikos ( () Pharmacy Department, Brigham and Women's Hospital, 75 Francis Street, Boston, MA 02115, USA

e-mail: jfanikos@partners.org associated with serious thrombotic events while dabigatran has been associated with serious bleeding [2, 3]. Since anticoagulant use enhances the risk for Emergency Department visits by as much as 35 -fold [4], clinicians must be familiar with anticoagulants, their pharmacological properties, pharmacodynamics, dosing, monitoring, and toxicity.

\section{Pathophysiology}

The coagulation cascade is triggered by tissue factor release from tissue trauma or vascular injury (Fig. 1) [5]. Tissue factor forms a complex with factor VIIa in the presence of calcium and cleaves clotting factors $\mathrm{X}$ and IX to their activated forms (factors Xa and IXa). The prothrombinase complex is then assembled on a phospholipid membrane and cleaves prothrombin (factor II) to factor IIa (thrombin). Thrombin is one of the most potent activators of primary (platelet-mediated) and secondary (clotting factor-mediated) hemostasis. Thrombin may also potentiate clot formation by fibrin polymerization, platelet receptor activation, endothelium activation, and activation of factors V, VIII, XI, and XIII. Anticoagulant agents can inhibit thrombogenesis by altering various pathways within the clotting cascade or by targeting thrombin directly, attenuating thrombin generation. Indirect inhibitors, however, target and bind to naturally occurring plasma cofactors, such as antithrombin (AT), catalyzing their interaction with clotting enzymes [5].

\section{Pharmacology of Heparins and Fondaparinux}

Unfractionated heparin (UFH) and low molecular weight heparin (LMWH) are the anticoagulants of choice in acute thrombosis due to their rapid onset of 
EXTRINSIC PATHWAY

(physiologic activation)

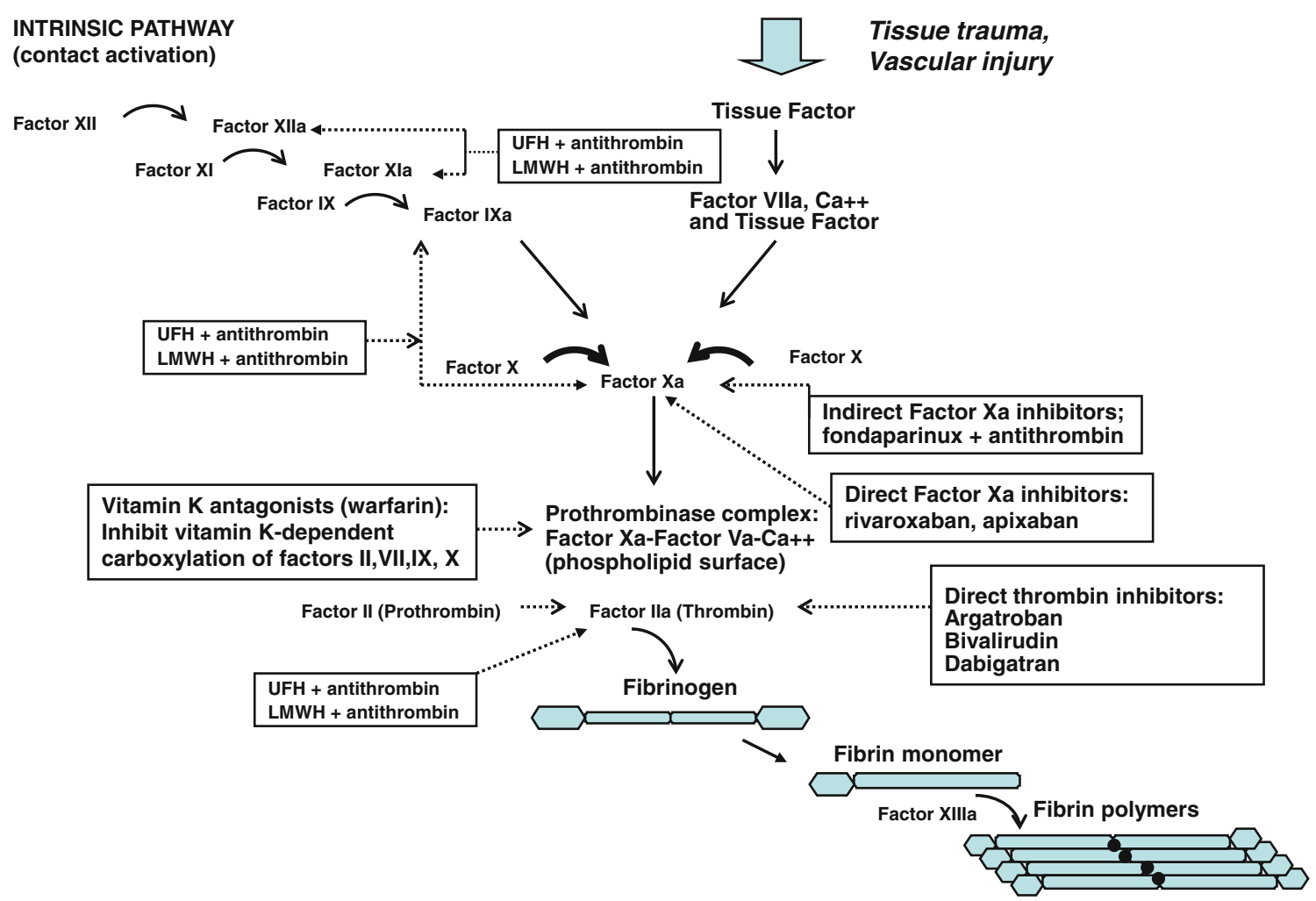

Fig. 1 The coagulation cascade is comprised of the intrinsic (contact activation) pathway and the extrinsic (tissue factor) pathway. Each pathway generates a series of reactions in which inactive circulating enzymes and their co-factors are activated. These activated factors then catalyze the next reactions in the cascade. Thrombin plays a pivotal role by triggering the conversion of soluble fibrinogen to

antithrombotic activity. Since heparins are dependent on the presence of AT for clotting factor inhibition, they are considered indirect anticoagulants (Table 1) [6••, 7, 8]. Heparins have no fibrinolytic activity and will not lyse existing thrombi. Heparins contain an active pentasaccharide sequence that binds to AT. Once heparin binds and activates AT, it can readily dissociate and bind to additional AT, providing a continuous anticoagulant effect. This binding produces a conformational change, accelerating AT binding and inactivation of coagulation factors XIIa, IXa, XIa, Xa and thrombin. The active pentasaccharide sequence responsible for catalyzing AT is found on one-third and one-fifth of the chains of UFH and LMWH, respectively. Fondaparinux is a synthetic analog of the naturally occurring pentasaccharide found in heparins $[6 \bullet \bullet, 7,8]$. Fondaparinux selectively and irreversibly binds to AT. This results in neutralization of factor Xa, which ultimately inhibits thrombin formation and thrombus development. insoluble fibrin monomers, which serve as the foundation for thrombus formation. Thrombin also activates factors VIII, V, and XIII. Factor XIII generates the covalent bonds that link fibrin strands ensuring structural integrity. Anticoagulants, either through their interaction with Antithrombin (AT) or through a direct inhibition of thrombin, interrupt these enzymatic reactions

\section{Unfractionated Heparin}

Pharmacodynamics and Monitoring

Intravenous (IV) infusion or subcutaneous injections are the available routes for UFH administration and IV is preferred [6••, 7-9]. When given via subcutaneous injection for therapeutic anticoagulation, doses need to be large enough ( $>30,000 \mathrm{U} /$ day) to overcome UFHs low bioavailability. UFH readily binds to plasma proteins, which contributes to its variable anticoagulant response after parenteral administration. Despite these limitations IV administration rapidly achieves therapeutic plasma concentrations that can be effectively monitored and adjusted based on infusion rates [7].

UFH clearance from the systemic circulation is doserelated and occurs through two independent mechanisms $[6 \bullet \bullet, 8]$. The initial phase is the rapid and saturable binding to endothelial cells, macrophages, and local proteins where 
Table 1 Comparison of the pharmacologic features of heparin and its derivatives

\begin{tabular}{llll}
\hline Features & Heparin & LMWH & Fondaparinux \\
\hline Source & Biological & Biological & Synthetic \\
Molecular weight (Da) & 15,000 & 5,000 & 1,500 \\
Target & Xa:IIa & Xa $>$ IIa & Xa \\
Bioavailability (\%) & 30 & 90 & 100 \\
Half-life (h) & 1 & 4 & 17 \\
Renal excretion & No & Yes & Yes \\
Protamine reversal & Complete & Partial & None \\
Incidence of HIT $(\%)$ & $<5.0$ & $<1.0$ & Case reports \\
\hline
\end{tabular}

Da Dalton, $h$ hours, HIT heparin-induced thrombocytopenia

UFH is depolymerized. The second phase is a slower, nonsaturable, renal-mediated clearance. At therapeutic doses, UFH is cleared primarily via depolymerization, with the higher molecular weight chains being cleared more rapidly than lower weight counterparts. As clearance becomes dependant on the kidney, increased or prolonged UFH dosing provides a disproportionate increase in both the intensity and the duration of the anticoagulant effect.

The anticoagulant response to UFH administration is monitored using the activated partial thromboplastin time (aPTT). The aPTT should be measured every $6 \mathrm{~h}$ with IV administration, and doses adjusted accordingly, until the patient has sustainable therapeutic levels. Once steady state is reached the frequency of monitoring can be extended $[8,10]$.

To overcome variables delivering UFH, weight-based dosing nomograms are recommended for treatment of thromboembolic disease. Dosing nomograms have been associated with significantly higher initial UFH doses, shorter time to therapeutic activated aPTT, and no increase in bleeding events. UFH dosing nomograms will differ from hospital to hospital due to differences in thromboplastin agents and inter-laboratory standardizations in aPTT measurements [10].

\section{Clinical Indications}

Clinical indications for UFH include treatment of acute coronary syndromes (ACS), treatment or prevention of venous thromboembolism (VTE), bridge therapy for atrial fibrillation (AF), and cardioversion (Table 2) [6••, 11-13]. UFH utilization has diminished with LMWH and fondaparinux availability and their superior pharmacokinetic profiles [6••, 7]. UFH, with a short half-life and reversal capability, remains the best option in patients requiring higher UFH doses, in patients with underlying bleeding risk, or in those critically ill with organ dysfunction. Patients with fluctuating renal function or with a creatinine clearance less than $30 \mathrm{~mL} / \mathrm{min}$ are not candidates for LMWH or fondaparinux due to the risk of accumulation and increased bleeding risk [14]. When used for thromboprophylaxis in medical patients, three times daily UFH dosing provides better efficacy in preventing VTE events compared to twice daily dosing but generates more major bleeding episodes [15].

\section{Complications and Reversal of Effect}

The major complications of UFH therapy include bleeding (major bleeding, 0-7 \%; fatal bleeding, 0-3\%) and heparin-induced thrombocytopenia (HIT, 1-5\%). Patients receiving $\mathrm{UFH}$ for periods of more than 1 month are also at an increased risk for osteoporosis and development of vertebral fractures (approximately $2 \%$ incidence) [16]. Hemorrhagic episodes are associated with the intensity of anticoagulation, route of administration (continuous infusions are associated with lower rates), and concomitant use of glycoprotein (gp) IIB/IIIA inhibitors, aspirin or fibrinolytic therapy [16-18]. The relationship between supratherapeutic levels of UFH (elevated aPTT, heparin levels or anti-Xa levels) and major bleeding is not well established and has not been prospectively compared in clinical trials. Major bleeding can occur within therapeutic levels of anticoagulation. Patient-specific risk factors are the most important consideration when determining the bleeding risk, including: age, gender, renal failure, low body weight, and excessive alcohol consumption [16-18].

Anticoagulation management before and after surgery is a patient specific, risk versus benefit decision. It is based on the procedure and patient's risk factors for bleeding and thrombosis. For patients requiring peri-operative anticoagulation in elective procedures or surgery, discontinuing therapeutic IV UFH doses $4 \mathrm{~h}$ prior to the procedure and measuring an aPTT is usually sufficient, as normal hemostasis is restored in this time frame in most cases. If the aPTT remains elevated, then hourly measurements are advised until the aPTT returns to baseline [19-21]. Therapeutic UFH therapy can be restarted $12 \mathrm{~h}$ after major surgery, but should be delayed longer for evidence of continued bleeding. In patients receiving low-dose UFH subcutaneously, there is no contraindication to neuraxial techniques, as the risk for developing spinal hematoma appears to be minimal. In patients who are to receive intraoperative anticoagulation with UFH, the UFH infusion should be started at least $1 \mathrm{~h}$ after needle placement. Indwelling catheters should be removed $2-4 \mathrm{~h}$ after discontinuation of the UFH infusion and only after the patient's coagulation status has been assessed [22].

Since UFH has a short half-life, reversal is not required in most bleed episodes. The treatment of clinically severe UFHrelated bleeding includes anti-heparin therapy (protamine sulfate), transfusion therapy, and supportive care. Protamine dosing is dependent on timing of the last UFH dose. For 


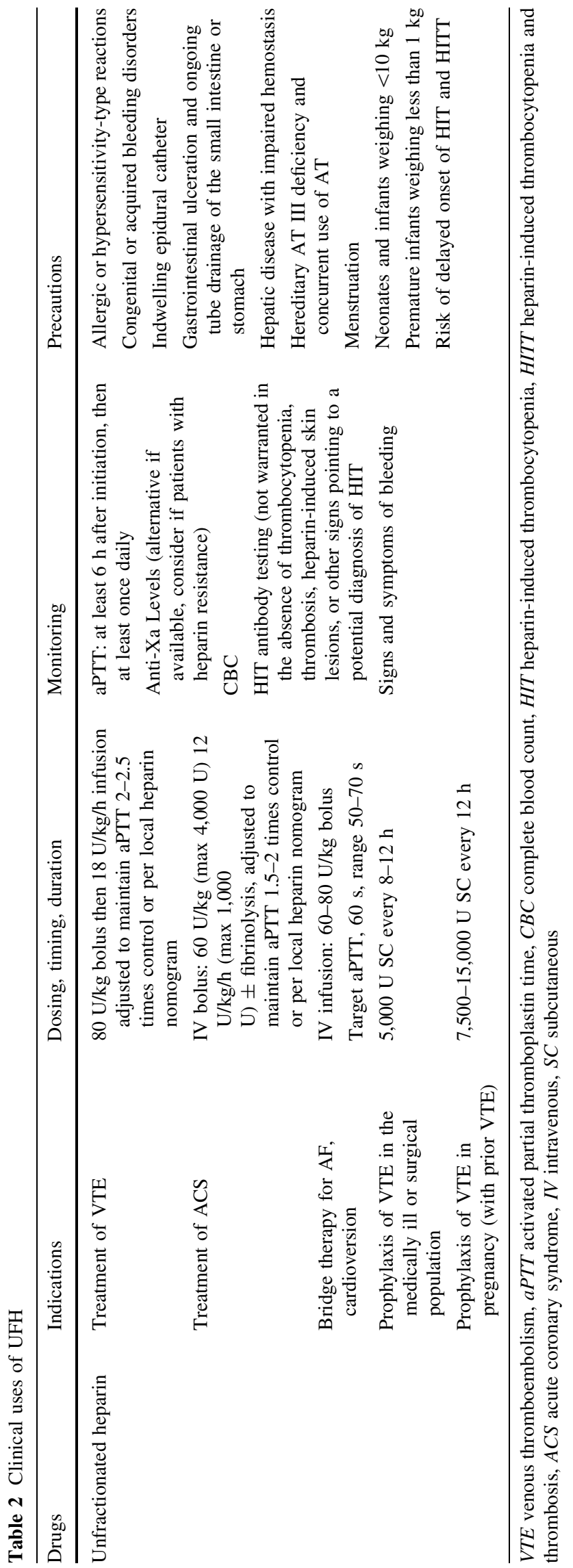

immediate reversal ( $<30$ min since the last UFH dose), $1 \mathrm{mg}$ of protamine is administered for every $100 \mathrm{U}$ of UFH and a follow up aPTT can evaluate the reversal response. When UFH is given as a continuous IV infusion, only UFH delivered during the preceding $2-2.5 \mathrm{~h}$ should be included in the calculation to determine the protamine dose. If the UFH dose is unknown, protamine $50 \mathrm{mg}$ can be administered slowly over $10 \mathrm{~min}$ followed by serial measurements of aPTT. Severe adverse reactions to protamine, such as hypotension and bradycardia, are common. Reaction severity may be reduced by slowing the administration over 1-3 min (maximum administration rate is $5 \mathrm{mg} / \mathrm{min}$ ). Allergic responses to protamine are more common in patients who have been previously exposed to the drug for UFH neutralization, or treated with protamine-containing insulin (neutral protamine Hagedorn insulin), have undergone vasectomy, or have hypersensitivity to fish. Patients at risk of developing antiprotamine antibodies can be pretreated with corticosteroid and anti-histamine medications [23-24].

\section{Low Molecular Weight Heparins}

\section{Pharmacodynamics and Monitoring}

LMWHs have increased bioavailability after subcutaneous injection, renal clearance that is dose-independent, and a longer half-life (17-21 h) when compared to UFH. LMWHs are administered in fixed doses for thromboprophylaxis, or in total body weight adjusted doses for therapeutic anticoagulation (Table 3) [5, 25].

With their predictable dose response (peak anti-Xa activity occurring $3-5 \mathrm{~h}$ after injection) laboratory monitoring is usually not necessary. Anti-Xa monitoring is an option in high-risk patient populations (renal insufficiency, obesity, pregnancy, non-compliance) where dosing adjustments may be required to tailor therapy. In these cases anti-Xa plasma levels are drawn $4 \mathrm{~h}$ after administration, and subsequent dosing adjusted to peak target levels of $0.5-1.1 \mathrm{IU} / \mathrm{mL}[26,27]$. Anti-Xa tests should be monitored and interpreted per the manufacturer of the specific LMWH being used.

\section{Clinical Indications}

For medically ill and post-operative patients requiring parenteral VTE prophylaxis, LMWHs have become a suitable replacement for UFH $[28,29]$. LMWHs require fewer injections and produce fewer adverse events. In hospitalized medical patients receiving thromboprophylaxis, LMWH was associated with a lower risk of deep vein thrombosis (DVT), fewer injection site hematomas, and no differences in bleeding when compared with UFH [30]. 


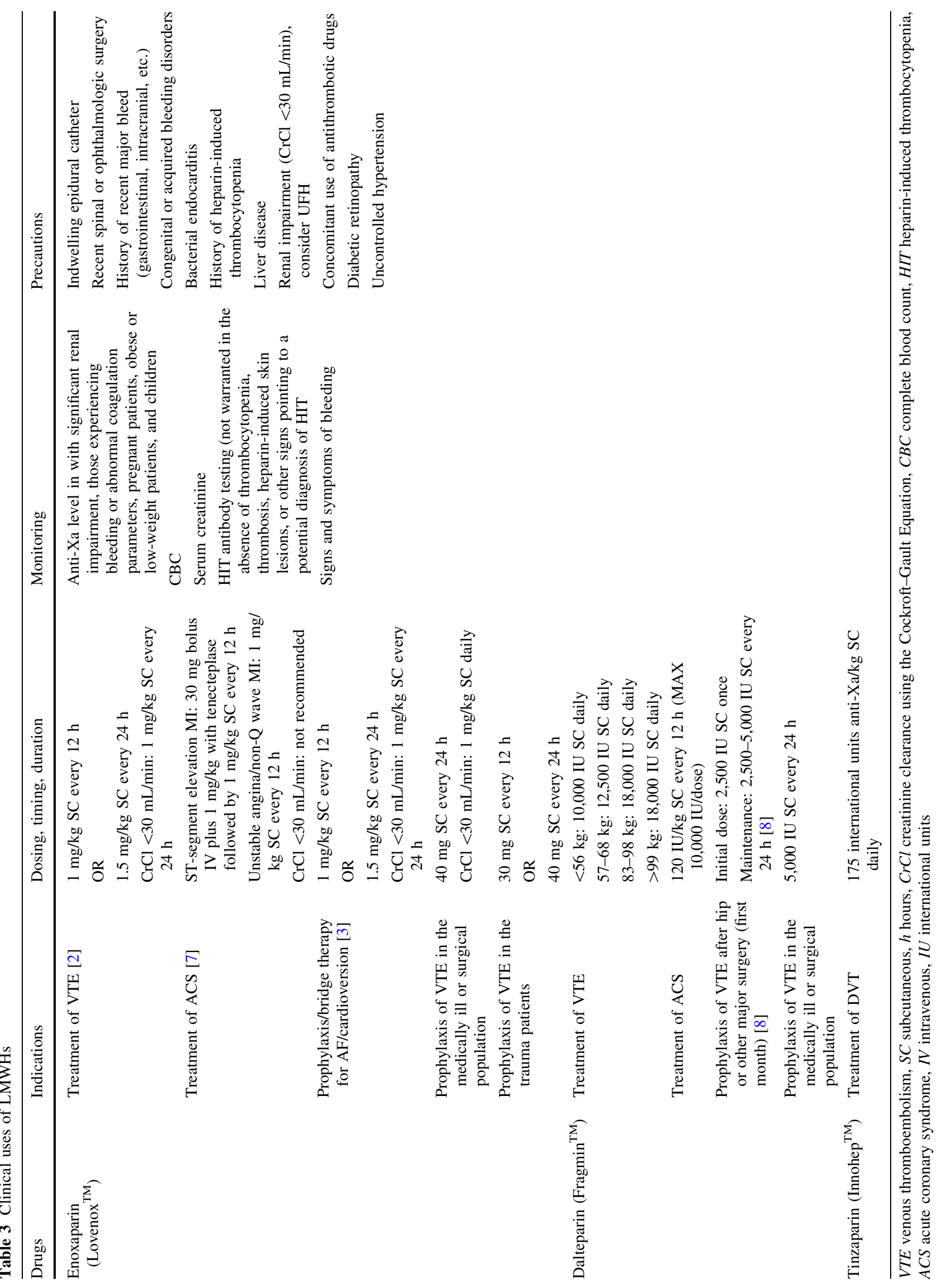


LMWHs have largely replaced IV UFH in patients with acute VTE who are able to continue therapy, unmonitored in the ambulatory setting [31]. In ACS, patients with STsegment elevation myocardial infarction treated with fibrinolysis and LMWH had a lower incidence of death or non-fatal recurrent myocardial infarction but a higher rate of major bleeding than those treated with fibrinolysis and UFH [32]. Similarly, in unstable angina/non-ST-segment elevation myocardial infarction, LMWH therapy reduced the incidence of death, myocardial infarction, or urgent revascularization when compared to UFH [33].

\section{Complications and Reversal of Effect}

Hemorrhage is the major complication of LMWH, with some data supporting decreased rates of bleeding compared to UFH. Rates of fatal bleeding are reported in $0-0.8 \%$ and major bleeding in $0-3 \%$ of patients [16]. In the surgical setting, peri-procedural thromboembolic risk assessment, bleeding risk assessment, and physician preference will play a role in determining whether LMWH prophylactic dosing is continued or withheld. For patients receiving therapeutic LMWH dosing, discontinuation should be considered $12-24 \mathrm{~h}$ prior to procedure, or longer in patients with renal dysfunction. Therapeutic doses of LMWH should not be restarted for $24 \mathrm{~h}$ after a major procedure or after neuraxial anesthesia [19, 32].

In the setting of overdose or life-threatening hemorrhage, protamine is administered IV. Protamine does not fully reverse LMWH but can neutralize the AT effect. Because longer heparin chains bind to protamine, protamine completely reverses the anti-factor IIa activity of LMWH but only reverses $60 \%$ of the anti-factor Xa activity. If immediate reversal is warranted within $8 \mathrm{~h}$ of LMWH administration, a protamine dose of $1 \mathrm{mg}$ neutralizes $100 \mathrm{U}$ anti-Xa or $1 \mathrm{mg}$ of LMWH. If bleeding continues, a second dose of $0.5 \mathrm{mg}$ of protamine per $100 \mathrm{U}$ anti-Xa may be administered. Smaller protamine doses are required if the LMWH administration interval is beyond $8 \mathrm{~h}[34,35]$.

HIT and HIT with thrombosis (HITT) are immunemediated disorders that result from antibodies being formed against the heparin-platelet factor IV complex. The incidence of HITT in critically ill patients ranges from 1 to $5 \%$ and is associated with the development of thrombocytopenia and life-threatening thrombosis in approximately $30-50 \%$ of HIT positive patients [36]. This immunemediated response typically occurs in patients exposed to UFH or LMWH for 5-7 days, or sooner if the patient was previously exposed. A $50 \%$ decrease in platelet count occurring 4-10 days after the initiation of UFH or LMWH therapy or formation of a new thrombus while anticoagulated may be indicative of HIT. Platelet counts should be measured prior to the initiation of UFH or LMWH and monitored every other day for the first 4-10 days of therapy. The incidence of HIT is approximately one-tenth lower with LMWH than with UFH [37]. In the setting of a HIT allergy or if positive HIT antibodies have been detected, LMWH cannot be used due to cross reactivity between glycosaminoglycans. Direct thrombin inhibitors (DTIs) are the treatment of choice for patients with HIT or HITT [38, 39].

Osteoporosis reportedly occurs less frequently in patients treated with LMWH as compared to UFH, and it typically is associated with long-term therapy [6••].

\section{Fondaparinux}

Pharmacodynamics and Monitoring

After subcutaneous administration, fondaparinux is rapidly and completely absorbed, exhibiting a half-life of 17-21 h in patients with normal renal function $[6 \bullet \cdot]$. Fondaparinux is excreted primarily unchanged in the urine with clearance reduced in patients with renal impairment. Similar to LMWH, with predictable pharmacokinetics, monitoring anti-Xa levels is not recommended during fondaparinux administration.

\section{Clinical Indication}

Fondaparinux has been proven to be at least as safe and effective as treatment of DVT and pulmonary embolism (PE) as LMWH and UFH, respectively [40, 41] (Table 4). Fondaparinux has been studied extensively for thromboprophylaxis in medically ill and surgical patients [42, 43]. In three trials fondaparinux showed superior efficacy in reducing VTE in patients undergoing knee arthroplasty, hip arthroplasty, and hip fracture surgery [44-46]. In a combined analysis, the overall incidence of major bleeding was statistically higher with fondaparinux $(2.7 \%)$ compared with LMWH (1.7\%) [47]. However, the incidence of clinically relevant bleeding, as defined as bleeding leading to death, reoperation, or occurring in a critical organ, did not differ between the agents. The differences in efficacy and safety outcomes could be related to dosing as well as the timing of peri-operative drug administration. The administration of fondaparinux given less than $6 \mathrm{~h}$ after surgery has been associated with an increased frequency of major bleeding [48]. Holding therapy for at least $6 \mathrm{~h}$ postprocedure may be recommended in patients at risk of bleeding. Fondaparinux may be a potential option for thromboprophylaxis in the setting of an HIT allergy but no conclusive data is available [49]. While fondaparinux has been studied in ACS, it has not received Food and Drug Administration (FDA) approval. 


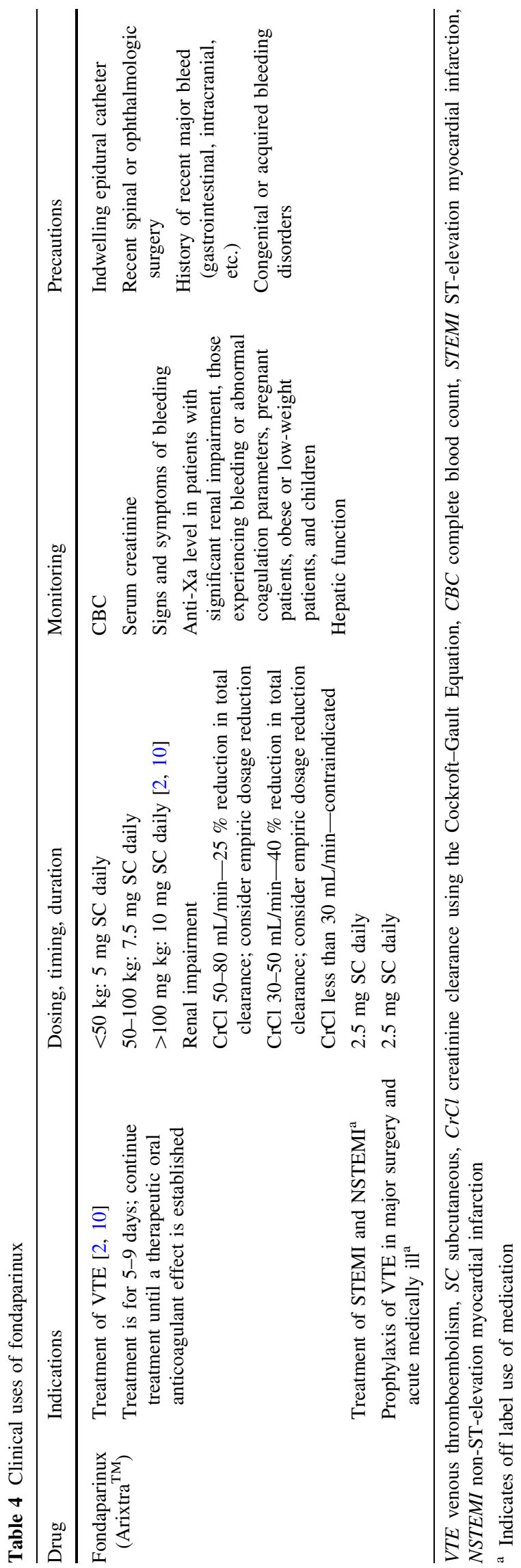

Complications and Reversal of Effect

Fondaparinux is contraindicated in patients with severe renal impairment (calculated creatinine clearance less than $30 \mathrm{~mL} /$ min). Fondaparinux should not be used for VTE prophylaxis in patients weighing less than $50 \mathrm{~kg}$. Fondaparinux reversal is further complicated by its prolonged half-life [50]. While no specific antidote exists for the fondaparinux-related hemorrhage, recombinant activated factor VII (rFVIIa) administration can normalize coagulation times and thrombin generation [51].

Direct Thrombin Inhibitors (DTIs)

DTIs exert their antithrombotic effect through direct, selective, and reversible binding to the active site of thrombin. This leads to inhibition of thrombin-catalyzed or -induced reactions, including fibrin formation, activation of coagulant factors V, VIII, XIII, protein C, and platelet aggregation. The hirudin analogs, desirudin and bivalirudin, and argatroban are three currently approved DTIs [52].

Pharmacology, Pharmacodynamics, and Monitoring

Bivalirudin and desirudin are synthetic analogs of r-hirudin that exert anticoagulant activity by reversible binding at the enzymatic catalytic site and the anion binding site of thrombin. Argatroban, derived from the amino acid arginine, is a small synthetic thrombin inhibitor that reversibly binds non-covalently to thrombin active site [52].

The DTIs differ in their pharmacokinetic parameters (Table 5) [52]. Bivalirudin has the shortest half-life, making it a particularly useful agent in the procedural or peri-procedural period. DTI selection often depends on patientspecific characteristics such as age, compromised cardiac function, hemodynamic instability, and hepatic or renal dysfunction $[52,53]$. Critically ill patients typically require lower infusion rates than recommended by the manufacturer due to the presence of comorbidities and organ dysfunction. DTIs are monitored using aPTT, with a goal of 1.5-3 times control or baseline (argatroban), 1.5-2.5 times control (bivalirudin) (Table 6). Desirudin does not need routine coagulation monitoring. The aPTT level should be measured every 6 h until the patient has sustainable therapeutic levels, then the frequency of monitoring can be extended. Because of inconsistencies in aPTT measurements, the plasma diluted thrombin time has shown to be an alternative to for monitoring DTI levels, especially in patients with lupus inhibitors or low levels of vitamin K-dependent factors [54].

\section{Clinical Indications}

DTIs can be used as an alternative anticoagulant to UFH for the treatment of HIT or HIT-T [55]. Argatroban 
Table 5 Pharmacokinetic and pharmacodynamic properties of DTIs

\begin{tabular}{|c|c|c|c|}
\hline Feature & Desirudin & Argatroban & Bivalirudin \\
\hline Molecular weight (Da) & 6963 & 526 & 2180 \\
\hline $\begin{array}{l}\text { FDA-approved } \\
\text { indication }\end{array}$ & $\begin{array}{l}\text { Prophylaxis of DVT in patients } \\
\text { undergoing elective hip replacement } \\
\text { surgery }\end{array}$ & $\begin{array}{l}\text { Management of HIT, or use in } \\
\text { patients with HIT who are } \\
\text { undergoing PCI }\end{array}$ & $\begin{array}{l}\text { Use in patients with or at risk for HIT } \\
\text { or HITTS who are undergoing PCI }\end{array}$ \\
\hline $\begin{array}{l}\text { Primary elimination } \\
\text { route }\end{array}$ & Renal & Hepatic & Enzymatic \\
\hline Elimination half-life & $\begin{array}{l}\mathrm{SC}=120 \mathrm{~min} \\
\mathrm{IV}=60 \mathrm{~min}\end{array}$ & $39-51 \mathrm{~min}$ & $10-24 \min$ \\
\hline $\begin{array}{l}\text { Fraction eliminated } \\
\text { unchanged by kidney } \\
(\%)\end{array}$ & $40-50$ & 16 & 20 \\
\hline $\begin{array}{l}\text { Laboratory test to } \\
\text { monitor }\end{array}$ & Not required & aPTT, ECT & aPTT, ACT, ECT \\
\hline Target range & $\mathrm{n} / \mathrm{a}$ & aPTT: $1.5-3 \times$ control & aPTT: $1.5-2.5 \times$ control \\
\hline Effects on INR & Minimal & Moderate to clinically significant & Minimal to moderate \\
\hline
\end{tabular}

Da Dalton, FDA Food and Drug Administration, HIT heparin-induced thrombocytopenia, HITTS HIT with thrombosis syndrome, PCI percutaneous coronary intervention, $S C$ subcutaneous, $I V$ intravenous, aPTT activated partial thromboplastin time, ECT ecarin clotting time, $A C T$ activated clotting time, INR international normalized ratio

Table 6 Clinical uses of DTIs

\begin{tabular}{|c|c|c|c|c|}
\hline Drugs & Indications & Dosing, timing, duration & Monitoring & Precautions \\
\hline \multirow[t]{4}{*}{$\begin{array}{l}\text { Bivalirudin } \\
\left.\text { (Angiomax }^{\mathrm{TM}}\right)\end{array}$} & \multirow{2}{*}{$\begin{array}{l}\text { PCI (with or without } \\
\text { glycoprotein IIB/IIIA } \\
\text { inhibitor) }\end{array}$} & $\begin{array}{l}0.75 \mathrm{mg} / \mathrm{kg} \text { IV bolus dose, followed by an infusion } \\
\text { of } 1.75 \mathrm{mg} / \mathrm{kg} / \mathrm{h} \text { for the duration of the procedure }\end{array}$ & $\begin{array}{l}\text { CBC } \\
\text { aPTT }\end{array}$ & $\begin{array}{l}\text { Indwelling epidural } \\
\text { catheter }\end{array}$ \\
\hline & & $\begin{array}{l}\mathrm{CrCl} \text { less than } 30 \mathrm{~mL} / \mathrm{min} \text {, a reduction of initial } \\
\text { infusion rate to } 1 \mathrm{mg} / \mathrm{kg} / \mathrm{h} \text { should be considered; } \\
\text { no bolus dose reduction is necessary }\end{array}$ & \multirow{2}{*}{$\begin{array}{l}\text { PT/INR (false } \\
\text { elevation } \\
\text { while on } \\
\text { infusion) }\end{array}$} & $\begin{array}{l}\text { Recent major, spinal or } \\
\text { ophthalmologic } \\
\text { surgery }\end{array}$ \\
\hline & Treatment of $\mathrm{ACS}^{\mathrm{a}}$ & $\begin{array}{l}\text { Initial IV bolus dose of } 0.1 \mathrm{mg} / \mathrm{kg} \text {, followed by } \\
0.25 \mathrm{mg} / \mathrm{kg} / \mathrm{h} \text {. }\end{array}$ & & \multirow{2}{*}{$\begin{array}{l}\text { History of recent major } \\
\text { bleed } \\
\text { (gastrointestinal, } \\
\text { intracranial, etc.) }\end{array}$} \\
\hline & $\begin{array}{l}\text { Treatment and prophylaxis } \\
\text { of } \text { HITT }^{\mathrm{a}}\end{array}$ & $\begin{array}{l}0.15-0.2 \mathrm{mg} / \mathrm{kg} / \mathrm{h} \text {, titration to aPTT } 1.5-2.5 \text { times } \\
\text { control }\end{array}$ & \multirow{6}{*}{$\begin{array}{l}\text { Blood pressure } \\
\text { Heart rate } \\
\text { ECG } \\
\text { Renal function } \\
\quad \text { (bivalirudin) } \\
\text { Hepatic } \\
\quad \text { function } \\
\text { (argatroban) }\end{array}$} & \\
\hline \multirow[t]{5}{*}{ Argatroban } & \multirow[t]{3}{*}{$\begin{array}{l}\text { Treatment and prophylaxis } \\
\text { of HITT }\end{array}$} & $\begin{array}{l}0.5-1.2 \mu \mathrm{g} / \mathrm{kg} / \mathrm{min} \text { continuous IV infusion to start } \\
\text { titration to goal aPTT of } 1.5-3 \text { times baseline }\end{array}$ & & $\begin{array}{l}\text { Congenital or acquired } \\
\text { bleeding disorders }\end{array}$ \\
\hline & & $\begin{array}{l}\text { Begin VKA therapy, measure INR daily. Stop } \\
\text { argatroban when INR }>4 \text {. Repeat INR in } 4-6 \mathrm{~h} \text {, }\end{array}$ & & $\begin{array}{l}\text { Recent cerebrovascular } \\
\text { accident }\end{array}$ \\
\hline & & $\begin{array}{l}\text { if INR is below desired range then resume } \\
\text { argatroban infusion }\end{array}$ & & $\begin{array}{l}\text { Hepatic impairment } \\
\text { (argatroban) }\end{array}$ \\
\hline & \multirow[t]{2}{*}{ PCI } & Bolus: $350 \mu \mathrm{g} / \mathrm{kg}$ & & \multirow{2}{*}{$\begin{array}{l}\text { Renal dysfunction } \\
\text { (bivalirudin) }\end{array}$} \\
\hline & & $\begin{array}{l}\text { Initial infusion: } 25 \mu \mathrm{g} / \mathrm{kg} / \mathrm{min} \text { maintain ACT } \\
\text { greater than } 300 \text { seconds }\end{array}$ & & \\
\hline Desirudin & $\begin{array}{l}\text { Prophylaxis of DVT in } \\
\text { patients undergoing } \\
\text { elective hip replacement } \\
\text { surgery }\end{array}$ & $\begin{array}{l}15 \mathrm{mg} \text { SC every } 12 \mathrm{~h} \text { given } 5-15 \mathrm{~min} \text { prior to } \\
\text { surgery but before induction of regional block } \\
\text { anesthesia (if used) }\end{array}$ & & \\
\hline
\end{tabular}

$P C I$ percutaneous coronary intervention, $I V$ intravenous, $C r C l$ creatinine clearance using the Cockroft-Gault Equation, $C B C$ complete blood count, $a P T T$ activated partial thromboplastin time, $A C T$ activated clotting time, $P T$ prothrombin time, INR international normalized ratio, $E C G$ echocardiogram, HITT heparin-induced thrombocytopenia and thrombosis, VKA vitamin $\mathrm{K}$ antagonist, ACS acute coronary syndrome

${ }^{\text {a }}$ Indicates off label use of medication

administration significantly reduced the rates of thromboembolic complications in patients with HIT [56]. Bivalirudin has been safely used in critically ill and HIT patients [57]. Argatroban and bivalirudin are indicated as an anticoagulant for thrombosis prevention in patients undergoing percutaneous coronary intervention (PCI). Bivalirudin is indicated for use as an anticoagulant in the treatment of patients with moderate to high-risk ACS, 
unstable angina/non-ST-segment elevation myocardial infarction who are undergoing early invasive management, and in patients undergoing PCI (Table 6) [5].

\section{Complications and Reversal of Effect}

Hemorrhage is the most common complication with DTIs and no specific reversal agent is available. Anecdotally, rFVIIa has been reported to be useful and could be considered for immediate treatment of life-threatening hemorrhage [58]. DTIs can produce a misleading elevation in the international normalized ratio (INR), complicating the transition to warfarin in HIT. A clinical strategy to bridge safely and effectively should be undertaken in order to avoid thrombosis or bleeding. Steps in a bridging strategy include determining a baseline INR while on the DTI, identifying a target INR level (desired 1.5-2-point increase) while considering the INR elevation induced by the DTI, once INR goal is reached withhold the DTI for 4-8 $\mathrm{h}$, and recheck the INR and aPTT. If the INR is $2-3$ with an aPTT close to baseline after the clinician accounts for the independent warfarin-related elevation in the aPTT, the DTI can be discontinued [49].

\section{Oral Anticoagulants-Vitamin K Antagonists}

Vitamin K antagonists (VKAs) produce their anticoagulant effect by inhibiting vitamin $\mathrm{K}$ epoxy reductase, which is required for the conversion of vitamin $\mathrm{K}$ to its active form vitamin $\mathrm{KH} 2$. Vitamin $\mathrm{K}$ dependant proteins such as clotting factors II, VII, IX, and $\mathrm{X}$ require $\gamma$-carboxylation by vitamin $\mathrm{KH} 2$ for biological activity [59•].

The relationship between the dose of warfarin and the response varies between patients and is modified by genetic and environmental factors (dietary intake, drug interactions, critical illness, etc.) that can influence the absorption of warfarin, its pharmacokinetics, and its pharmacodynamics $[59 \bullet, 60 \bullet, 61-63]$.

A wide dosing range is required to maintain a therapeutic INR with relatively low doses often required for the elderly and patients with underlying comorbidities. Nomogram based dosing is considered safer and more effective at reaching targeting INR goals [64]. Larger initial doses suppress proteins $\mathrm{C}$ and $\mathrm{S}$, producing a hypercoagulable response and are associated with overanticoagulation and higher rates of bleeding.

\section{Clinical Indications}

Warfarin is effective for the primary and secondary prevention of VTE, for the prevention of systemic embolism in patients with prosthetic heart valves or AF, for the primary prevention of acute myocardial infarction in high-risk men, and for the prevention of stroke, recurrent infarction, or death in patients with acute myocardial infarction (Table 7) [59•, 65-68].

\section{Complications and Reversal of Effect}

Bleeding is a major concern with warfarin therapy due to the influence of environmental factors and drug interactions in the setting of a narrow therapeutic index. Treatment with VKA increases the risk of major bleeding by $0.3-0.5 \%$ per year and the risk of intracranial hemorrhage by approximately $0.2 \%$ per year compared to controls. The most important risk factors for hemorrhage in VKA therapy include: intensity of anticoagulant effect, time within therapeutic range, and patient characteristics. Higher goal INRs $($ INR $>3$ ) have been directly associated with increased rates of hemorrhage, and patients at high risk of bleeds may benefit from lower target goals [59•, 60•].

Reversal of warfarin's anticoagulant effect requires withholding therapy. The duration of effect can last up to several days in the absence of reversal agent administration. In patients with clinically significant bleeding, the administration of vitamin $\mathrm{K}$ is crucial to reversing the anticoagulant effects of VKAs. In the setting of an INR between 4.5 and 10 and no significant bleeding, the next doses of warfarin should be held and the INR evaluated [60 ]. When the INR is $>10$ and the patient has no significant signs of bleeding, the guidelines recommend holding warfarin and giving oral vitamin $K$. In the setting of serious/life-threatening bleeding at any INR, warfarin should be held and vitamin K $10 \mathrm{mg}$ by slow IV infusion is recommended. Higher doses of vitamin $\mathrm{K}$ are effective but may lead to VKA resistance for more than a week. Vitamin K may be given orally or parenterally, with the IV route providing a more rapid response. The intramuscular or subcutaneous routes are not recommended in the critically ill due to unpredictable absorption. In cases where immediate reversal of the INR is necessary the supplementation of clotting factors with fresh frozen plasma (FFP), or prothrombin complex concentrate (PCC) are more effective. PCCs contain more clotting factors in a smaller volume and have been shown to be more effective in the reversal of warfarin therapy. Recombinant factor VIIa may be of benefit in patients with refractory bleeding in the setting of elevated INRs [60, 61-69].

Non-hemorrhagic adverse events of warfarin include acute skin necrosis and limb gangrene; these uncommon complications are observed on the third to eighth day of therapy. Skin necrosis is caused by extensive thrombosis of the venules and capillaries within the subcutaneous fat, typically associated with protein $\mathrm{C}$ deficiencies. Limb gangrene, however, is due to massive outflow obstruction of the venous circulation of the limb, and can be seen in HIT patients treated with warfarin without adequate initial bridging with a DTI [59•]. 
Table 7 Clinical uses of warfarin

\begin{tabular}{|c|c|c|c|c|}
\hline Drug & Indications & Dosing, timing, duration & Monitoring & Precautions \\
\hline $\begin{array}{l}\text { Warfarin } \\
\text { Coumadin }^{\mathrm{TM}} \text {, } \\
\text { Jantoven }^{\mathrm{TM}} \text { ) }\end{array}$ & $\begin{array}{l}\text { Mechanical valve } \\
\text { in the atrial } \\
\text { position } \\
\text { Mechanical valve } \\
\text { in the mitral } \\
\text { position } \\
\text { Mechanical valve } \\
\text { in both the atrial } \\
\text { and mitral } \\
\text { position } \\
\text { Bioprosthetic } \\
\text { valve in the } \\
\text { mitral position }\end{array}$ & $\begin{array}{l}\text { Initial dosing: } 2.5-10 \mathrm{mg} \text { every } 24 \mathrm{~h} \\
\text { (see precautions) titrated to range } \\
\text { INR: } 2.0-3.0 \text {; target of } 2.5 \\
\text { Initial dosing: } 2.5-10 \mathrm{mg} \text { every } 24 \mathrm{~h} \\
\text { (see precautions) titrated to range } \\
\text { INR: } 2.0-3.0 \text {; target of } 2.5 \\
\text { Initial dosing: } 2.5-10 \mathrm{mg} \text { every } 24 \mathrm{~h} \\
\text { (see precautions) titrated to range } \\
\text { INR: } 2.0-3.0 \text {; target of } 2.5 \\
\text { Initial dosing: } 2.5-5 \mathrm{mg} \text { every } 24 \mathrm{~h} \\
\text { (see precautions) titrated to range } \\
\text { INR: } 2.0-3.0 \text {; target of } 2.5 \\
\text { Initial dosing: } 2.5-5 \mathrm{mg} \text { every } 24 \mathrm{~h} \\
\text { (see precautions) titrated to range } \\
\text { INR: } 2.5-3.5 \text {; target of } 3.0 \\
\text { Initial dosing: } 2.5-5 \mathrm{mg} \text { every } 24 \mathrm{~h} \\
\text { (see precautions) titrated to target } \\
\text { INR: } 2.5-3.5 \text {; target of } 3.0\end{array}$ & $\begin{array}{l}\text { Signs and } \\
\text { symptoms } \\
\text { of } \\
\text { bleeding } \\
\text { CBC } \\
\text { PT/INR }\end{array}$ & $\begin{array}{l}\text { Lower initial dosing (less than } 5 \text { mg may be } \\
\text { warranted in patients who are debilitated, are } \\
\text { malnourished, have congestive heart failure, } \\
\text { have liver disease, have had recent major } \\
\text { surgery, or are taking medications known to } \\
\text { increase sensitivity to warfarin) } \\
\text { Cerebrovascular disease } \\
\text { Coronary disease } \\
\text { CYP2C9 and VKORC1 genetic variation } \\
\text { Moderate to severe hypertension } \\
\text { Malignancy } \\
\text { Renal impairment } \\
\text { Recent trauma } \\
\text { Malignancy } \\
\text { Collagen vascular disease } \\
\text { Conditions that increase risk of hemorrhage, } \\
\text { necrosis, and/or gangrene, pre-existing } \\
\text { Congestive heart failure } \\
\text { Sever diabetes } \\
\text { Excessive dietary vitamin K } \\
\text { Elderly or debilitated patients (lower dosing } \\
\text { may be required) } \\
\text { Hepatic impairment } \\
\text { Hyperthyroidism/hypothyroidism } \\
\text { Epidural catheters } \\
\text { Infectious diseases or disturbances of intestinal } \\
\text { flora, such as sprue or antibiotic therapy } \\
\text { Poor nutritional state } \\
\text { Protein C deficiency } \\
\text { Heparin-induced thrombocytopenia } \\
\text { Vitamin K deficiency }\end{array}$ \\
\hline
\end{tabular}

VTE venous thromboembolism, $h$ hours, INR international normalized ratio, $C B C$ complete blood count, $P T$ prothrombin time, $M I$ myocardial infarction

Patients on VKAs requiring surgery should hold therapy approximately 5 days prior to the intervention. Depending upon the patient's history and risk of VTE or arterial thromboembolism, bridging with LMWH or UFH may be warranted. VKA may be resumed $12-24 \mathrm{~h}$ post-surgery, depending on bleeding risk and hemostasis. Assessment of the INR should be undertaken before neuraxial anesthesia is performed. For patients with an indwelling catheter who are receiving warfarin, the catheter should be removed when the INR is less than 1.5. Patients with a low risk of bleeding may undergo surgery with an INR of 1.3-1.5 [19-21, 70].

Target-Specific Oral Anticoagulants

Dabigatran, rivaroxaban, and apixaban are novel oral anticoagulants that offer major advantages over current agents. They have rapid onset and more predictable anticoagulants response that eliminates the need for monitoring. Clinical trials have been completed with all three agents in the prevention and treatment of the three leading causes of cardiovascular death: myocardial infarction, stroke, and VTE. Novel agents have shown reduced or similar rates of thrombosis, major bleeding, and adverse events when weighed against either LMWH or warfarin.

Pharmacology, Pharmacodynamics, and Monitoring

Dabigatran etexilate mesylate is a prodrug. After oral administration, non-specific plasma and hepatic esterases hydrolyze the compound into the active anticoagulant, dabigatran [71]. Dabigatran is DTI that exerts its action through reversible, competitive binding to the active site on 
Table 8 Pharmacokinetic and pharmacodynamic properties of target-specific oral

anticoagulants

${ }^{\text {a }}$ P-glycoprotein (P-gp) inhibitors include verapamil, clarithromycin, and quinidine

b Cytochrome (CYP) P450 3A4 inhibitors include but are not limited to: ketoconazole, macrolide antibiotics, and protease inhibitors

\begin{tabular}{llll}
\hline Features & Dabigatran etexilate & Rivaroxaban & Apixaban \\
\hline Target & Thrombin & Factor Xa & Factor Xa \\
Prodrug & Yes & No & No \\
Dosing & Fixed & Fixed & Fixed \\
Bioavailability (\%) & 6 & 80 & 90 \\
Food effects & Delay $T_{\max } 2-4 \mathrm{~h}$ & Delays $T_{\max }$ & Not reported \\
Half-life (h) & $12-17$ & $5-9$ & 12 \\
Renal excretion (\%) & 80 & 65 & 25 \\
Coagulation monitoring & No & No & No \\
Antidote & None & None & None \\
Interactions & P-gp inhibitors & Combined P-gp and & Potent 3CYP3A4 inhibitors \\
& & CYP3A4 inhibitors & \\
\hline
\end{tabular}

thrombin. Furthermore, dabigatran indirectly exerts an anti-platelet effect by reducing thrombin's impact on promoting platelet activation and aggregation [72].

Dabigatran is eliminated through renal filtration with up to $80 \%$ of the dose excreted unchanged in urine (Table 8). Dabigatran's mean terminal elimination half-life is prolonged in patients with severe renal dysfunction. There is no antidote available to reverse or attenuate dabigatran's anticoagulant effect [72].

Rivaroxaban is an oral, highly selective, direct, competitive inhibitor of factor $\mathrm{Xa}$ [73]. Inhibition of factor $\mathrm{Xa}$ leads to interruption of the both intrinsic and extrinsic coagulation pathways, thus preventing thrombin generation and subsequent thrombus formation. Rivaroxaban's inhibition of both free and fibrin-bound factor Xa differentiates its action from LMWH or fondaparinux. Rivaroxaban exerts minimal effect on platelet function.

In patients with $\mathrm{CrCl} 15-30 \mathrm{~mL} / \mathrm{min}$, the dabigatran dose should be reduced to $75 \mathrm{mg}$ twice daily [71]. The manufacturer does not recommend the use of rivaroxaban in patients with an estimated creatinine clearance less than $15 \mathrm{~mL} / \mathrm{min}$ [74].

\section{Clinical Indications}

While dabigatran has been compared with enoxaparin for VTE prophylaxis, and with warfarin in acute VTE treatment and secondary prevention, it only has FDA approval for stroke prevention in AF (Table 9).

RE-LY was a non-inferiority trial designed to determine the long-term safety and efficacy of dabigatran administered twice daily as compared to warfarin (INR goal 2.0-3.0) in patients with non-valvular AF [75]. Patients were required to have at least one addition thromboembolism risk factor. The primary efficacy outcome was defined as the occurrence of stroke or systemic embolism. The dabigatran $150 \mathrm{mg}$ twice daily regimen was statistically superior to warfarin in reducing the rate of stroke and systemic embolism, $1.11 \%$ per year versus $1.69 \%$ per year, respectively $(p<0.001)$. As any other anticoagulant, bleeding is the major adverse event. In ReLY trial, the primary safety outcome was major bleeding. There was no difference in the rate of major bleeding in the dabigatran $150 \mathrm{mg}$ group compared with the warfarin group.

Rivaroxaban has been studied in a large clinical trial program and has FDA approval for a variety of indications. The orthopedic surgery program compared rivaroxaban to enoxaparin for VTE prevention in patients undergoing total hip and total knee arthroplasty [76-79]. The primary efficacy endpoint was total VTE, the composite of any DVT, non-fatal PE, and all-cause mortality. In the RECORD1, -2, -3 and -4 studies rivaroxaban $10 \mathrm{mg}$ daily was superior to enoxaparin and associated with a similar safety profile. Rivaroxaban has been evaluated for stroke prevention in patients with non-valvular AF [80]. In the ROCKET-AF trial rivaroxaban $20 \mathrm{mg}$ once daily was non-inferior to warfarin in reducing all-cause stroke and non-central nervous system embolism in with a similar rate of major bleeding. Rivaroxaban has been studied for the acute DVT and PE treatment and for the long-term secondary prevention of recurrent VTE [81, 82]. The EINSTEIN-DVT study found rivaroxaban $15 \mathrm{mg}$ twice daily for 3 weeks followed by $20 \mathrm{mg}$ daily was non-inferior to enoxaparin followed by a VKA in the prevention or recurrent VTE [81]. In the EINSTEIN-Extension trial, rivaroxaban $20 \mathrm{mg}$ daily extended for an additional 6-12 months significantly reduced recurrent VTE without an increase in major or clinically relevant non-major bleeding when compared with placebo. In EINSTEIN-PE rivaroxaban was found to be non-inferior to enoxaparin combined with a VKA in the prevention of recurrent VTE while providing a significant reduction in major bleeding [82]. 
Table 9 Clinical uses of target-specific oral anticoagulants

\begin{tabular}{|c|c|c|c|c|}
\hline Drugs & Indications & Dosing, timing, duration & Monitoring & Precautions \\
\hline $\begin{array}{l}\text { Dabigatran etexilate } \\
\left(\operatorname{Pradaxa}^{\circledR}\right)\end{array}$ & $\begin{array}{l}\text { Stroke and systemic } \\
\text { embolism } \\
\text { prophylaxis in } \\
\text { non-valvular AF }\end{array}$ & $\begin{array}{l}\mathrm{CrCl}>30 \mathrm{~mL} / \mathrm{min}: 150 \mathrm{mg} \text { twice } \\
\text { daily } \\
\mathrm{CrCl} 15-30 \mathrm{~mL} / \mathrm{min}: 75 \mathrm{mg} \text { twice } \\
\text { daily }\end{array}$ & $\begin{array}{l}\text { No specific assay } \\
\text { available }\end{array}$ & $\begin{array}{l}\text { Bioprosthetic heart valves } \\
\text { P-gp inducers and inhibitors }\end{array}$ \\
\hline \multirow[t]{4}{*}{ Rivaroxaban $\left(\right.$ Xarelto $\left.^{\circledR}\right)$} & $\begin{array}{l}\text { Stroke prophylaxis } \\
\text { in non-valvular AF }\end{array}$ & $\begin{array}{l}\mathrm{CrCl}>50 \mathrm{~mL} / \mathrm{min}: 20 \mathrm{mg} \text { once } \\
\text { daily with the evening meal } \\
\mathrm{CrCl} 15-50 \mathrm{~mL} / \mathrm{min}: 15 \mathrm{mg} \text { once } \\
\text { daily with the evening meal }\end{array}$ & $\begin{array}{l}\text { No specific assay } \\
\text { available }\end{array}$ & $\begin{array}{l}\text { Spinal/epidural anesthesia or } \\
\text { puncture } \\
\mathrm{CrCl}<15 \mathrm{~mL} / \mathrm{min} \text { in non- } \\
\text { valvular } \mathrm{AF}\end{array}$ \\
\hline & $\begin{array}{l}\text { Treatment of DVT } \\
\text { or PE }\end{array}$ & $\begin{array}{l}15 \mathrm{mg} \text { twice daily with food for } \\
21 \text { days then } 20 \mathrm{mg} \text { daily with } \\
\text { food for remaining treatment }\end{array}$ & & $\begin{array}{l}\mathrm{CrCl}<30 \mathrm{~mL} / \mathrm{min} \text { in treatment } \\
\text { or prevention of } \mathrm{DVT}, \mathrm{PE} \\
\mathrm{P} \text {-gp inducers or inhibitors }\end{array}$ \\
\hline & $\begin{array}{l}\text { DVT or PE } \\
\text { secondary } \\
\text { prophylaxis }\end{array}$ & $20 \mathrm{mg}$ once daily with food & & $\begin{array}{l}\text { CYP3A4 inducers or inhibitors } \\
\text { Pregnancy }\end{array}$ \\
\hline & $\begin{array}{l}\text { DVT prophylaxis } \\
\text { following hip or } \\
\text { knee replacement } \\
\text { surgery }\end{array}$ & $\begin{array}{l}10 \text { mg once daily for } 35 \text { days (hip } \\
\text { replacement) or } 12 \text { days (knee } \\
\text { replacement) }\end{array}$ & & \\
\hline Apixaban (Eliqiuis ${ }^{\circledR}$ ) & $\begin{array}{l}\text { Stroke and systemic } \\
\text { embolism } \\
\text { prophylaxis in } \\
\text { non-valvular AF }\end{array}$ & $\begin{array}{l}5 \mathrm{mg} \text { twice daily or } 2.5 \mathrm{mg} \text { twice } \\
\text { daily in patients with at least } \\
\text { two of: age }>80 \text { years, body } \\
\text { weight }<60 \mathrm{~kg} \text {, serum } \\
\text { creatinine }<1.5 \mathrm{mg} / \mathrm{dL}\end{array}$ & $\begin{array}{l}\text { No specific assay } \\
\text { available }\end{array}$ & \\
\hline
\end{tabular}

$\mathrm{CrCl}$ creatinine clearance, $\mathrm{DVT}$ deep vein thrombosis, $\mathrm{PE}$ pulmonary embolism

While apixaban has been evaluated in thromboprophylaxis following orthopedic surgery, secondary prevention of VTE, and ACSs, its sole FDA approval is in stroke prevention in AF [83•].

In the ARISTOTLE trial, investigators compared apixaban $5 \mathrm{mg}$ twice daily with warfarin titrated to a goal INR of 2-3 [84]. The primary outcome, a composite of stroke and systemic embolism, occurred significantly less frequently in the apixaban patients compared to the warfarin patients. Bleeding was significantly less frequent in the apixaban patients compared to the warfarin patients across several bleeding definitions tested.

\section{Complications and Reversal of Effect}

The most common adverse events reported with dabigatran include dyspepsia, dizziness, headache, dyspnea, and shortness of breath. Abdominal pain and gastritis-like symptoms may be related to the capsule formulation which can be combated by taking the medication with food [83•].

There are no specific coagulation assays for laboratory monitoring of novel oral anticoagulants. Thrombin time and aPTT can be used to detect the presence of dabigatran in the plasma [85]. Similarly, rivaroxaban and apixaban prolong prothrombin time and aPTT. The role of other newer assays (Heptest, prothrombinase-induced clotting time, Anti-FXa chromogenic assays) have yet to be established.

Currently, there is no antidote available to reverse dabigatran, rivaroxaban, or apixaban. In the event of overdose, the early use of activated charcoal is recommended [83.]. Cessation of dabigatran, rivaroxaban, or apixaban therapy may be sufficient to reverse any excessive anticoagulant effect due to their short half-lives. While dialysis, for 2-3 h removes up $60 \%$ of dabigatran, it has no impact on rivaroxaban or apixaban [85].

Limited data exists for treatment of life-threatening bleeding produced by novel anticoagulants. Recent trials have suggested PCCs or rFVIIa may offer benefit by normalizing coagulation parameters $[74,86 \bullet$, 87]. Their evaluation, use, and role in the clinical setting are still required. In the event of bleeding symptomatic treatment of the hemorrhage should be initiated [83•].

For the novel agents, confusion and debate may ensue if prescribed in patient populations, such as those with pregnancy, mechanical heart valves, and thrombophilias, where little study data and clinical experience exists. Similarly, surgical and invasive procedures add additional levels of complexity where therapy may be continued, interrupted, or replaced with short-term parenteral or 'bridge' therapy. 


\section{Conclusions}

UFH, LMWHs, fondaparinux, DTIs, and warfarin have been studied and employed extensively for prevention and treatment of thrombosis. Novel oral anticoagulants have emerged from clinical development and are expected to replace older agents with their ease of use and more favorable pharmacodynamic profiles. Hemorrhage is the main concerning adverse event with all anticoagulants. With their ubiquitous use, it becomes important for clinicians to have a sound understanding of anticoagulant pharmacology, dosing, monitoring, and toxicity. Working knowledge becomes crucial for intercepting and averting problems.

Disclosure No potential conflicts of interest relevant to this article were reported.

Open Access This article is distributed under the terms of the Creative Commons Attribution License which permits any use, distribution, and reproduction in any medium, provided the original author(s) and the source are credited.

\section{References}

Papers of particular interest, published recently, have been highlighted as:

- Of importance

•- Of major importance

1. Budnitz DS, Lovegrove MC, Shehab N, Richards CL. Emergency hospitalizations for adverse drug events in older Americans. N Engl J Med. 2011;365:2002-12.

2. Institute for Safe Medication Practices. QuarterWatch; monitoring FDA MedWatch reports. http://www.ismp.org/quarterwatch/ pdfs/2012Q1.pdf. Accessed 12012.

3. United States Food and Drug Administration. Pradaxa (dabigatran etexilate mesylate): drug safety communication-safety review of post-market reports of serious bleeding events. http:// www.fda.gov/Safety/MedWatch/SafetyInformation/SafetyAlerts forHumanMedicalProducts/ucm282820.htm. Accessed 13 Nov 2012.

4. Budnitz DS, Shehab N, Kegler SR, Richards CL. Medication use leading to emergency department visits for adverse drug events in older adults. Ann Intern Med. 2007;147:755-65.

5. Adams CD, Anger KA, Greenwood BC, Fanikos J. Antithrombotic pharmacotherapy. Chapter 110. In: Irwin and Rippe's intensive care medicine. 7th ed. Philadelphia, PA: Lippincott, Williams, and Wilkins; 2012. p. 1224-42.

6. • Garcia DA, Baglin TP, Weitz JI, Samama MM. Parenteral anticoagulants: antithrombotic therapy and prevention of thrombosis, 9th ed: American College of Chest Physicians EvidenceBased Clinical Practice Guidelines. Chest. 2012; 141:24S-43S. This article summarizes the pharmacology and pharmacodynamic properties of parenteral anticoagulants including; unfractionated heparin (UFH), low-molecular-weight heparins (LMWHs), fondaparinux, and the direct thrombin inhibitors. There is additional information provided on the dosing, therapeutic monitoring, reversal, and non-hemorrhagic complications.
7. Weitz DS, Weitz JI. Update on heparin: What do we need to know? J Thromb Thrombolysis. 2010;29:199-207.

8. Bussey H, Francis J, Heparin Consensus Group. Heparin overview and issues. Pharmacotherapy. 2004;24:103S-7S.

9. Hull RD, Raskob GE, Hirsh J, et al. Continuous intravenous heparin compared with intermittent subcutaneous heparin in the initial treatment of proximal-vein thrombosis. N Engl J Med. 1986;315:1109-14.

10. Raschke RA, Reilly BM, Guidry JR, et al. The weight-based heparin dosing nomogram compared with a "standard care" nomogram: a randomized controlled trial. Ann Intern Med. 1993; 119:874-81.

11. O'Gara PT, Kushner FG, Ascheim DD, et al. 2013 ACCF/AHA guideline for the management of ST-elevation myocardial infarction: a report of the American College of Cardiology Foundation/American Heart Association Task Force on Practice Guidelines. Circulation. doi:10.1016/CIR.0b013e3182742cf6.

12. Adams D, Bridges CR, Casey DE, et al. ACCF/AHA focused update of the guideline for the management of patients with unstable angina/non-ST-elevation myocardial infarction (updating the 2007 guideline and replacing the 2011 focused update): a report of the American College of Cardiology Foundation/ American Heart Association Task Force on Practice Guidelines. Circulation. 2012;126:875-910.

13. Turpie AGG, Robinson JG, Doyle DJ, et al. Comparison of highdose with low-dose subcutaneous heparin to prevent left ventricular mural thrombosis in patients with acute transmural anterior myocardial infarction. N Engl J Med. 1989;320:352-7.

14. Lim W, Dentali F, Eikelboom JW, Crowther MA. Meta analysis: low-molecular-weight heparin and bleeding in patients with severe renal insufficiency. Ann Intern Med. 2006;144:673-84.

15. King CS, Holley AB, Jackson JL, et al. Twice vs three times daily heparin dosing for thromboprophylaxis in the general medical population. A metaanalysis. Chest. 2007;131:507-16.

16. Schulman S, Beth RJ, Kearon C, Levine MN. Hemorrhagic complications of anticoagulant and thrombolytic treatment: American College of Chest Physicians Evidence-Based Clinical Practice Guidelines (8th Edition). Chest. 2008;133:257S-98S.

17. Saour JN, Sieck JO, Mamo LAR, Gallus AS. Trial of different intensities of anticoagulation in patients with prosthetic heart valves. N Engl J Med. 1990;322:428-32.

18. The Stroke Prevention in Atrial Fibrillation Investigators. Bleeding during antithrombotic therapy in patients with atrial fibrillation. Arch Intern Med. 1996;156:409-16.

19. Douketis JD, Berger PB, Dunn AS, et al. The perioperative management of antithrombotic therapy: American College of Chest Physicians Evidence-Based Clinical Practice Guidelines (8th Edition). Chest. 2008;133:299S-339S.

20. Kearon C, Hirsh J. Management of anticoagulation before and after elective surgery. N Engl J Med. 1997;336:1506-11.

21. Smith MS, Muir H, Hall R. Perioperative management of drug therapy, clinical considerations. Drugs. 1996;51:238-59.

22. Horlocker TT, Wedel DJ, Rowlingson JC, et al. Regional anesthesia in the patient receiving antithrombotic or thrombolytic therapy: American Society of Regional Anesthesia and Pain Medicine Evidence-Based Guidelines (Third Edition). Reg Anesth Pain Med. 2010;35:64-101.

23. Carr JA, Silverman N. The heparin-protamine interaction. A review. J Cardiovasc Surg (Torino). 1999;40:659-66.

24. McEvoy GK, editor. Protamine sulfate. In: AHFS drug information 2008. Bethesda: American Society of Health-System Pharmacists; 2008. p. 1595-7.

25. Barrowcliffe TW. Low molecular weight heparins. Br J Haematol. 1995;90:1-7.

26. Nutescu EA, Spinler SA, Wittkowsky A, Dager WE. Lowmolecular-weight heparin in renal impairment and obesity: 
available evidence and clinical practice recommendations across medical and surgical settings. Ann Pharmacother. 2009;43: 1064-83.

27. Mahé I, Aghassarian M, Drouet L, et al. Tinzaparin and enoxaparin given at prophylactic dose for eight days in medical elderly patients with impaired renal function: a comparative pharmacokinetic study. Thromb Haemost. 2007;97:581-6.

28. Kahn SR, Lim W, Dunn AS, et al. Prevention of VTE in nonsurgical patients: Antithrombotic Therapy and Prevention of Thrombosis, 9th ed: American College of Chest Physicians Evidence-Based Clinical Practice Guidelines. Chest. 2012;141: 195S-226S.

29. Gould MK, Garcia DA, Wren SM, et al. Prevention of VTE in nonorthopedic surgical patients: Antithrombotic Therapy and Prevention of Thrombosis, 9th ed: American College of Chest Physicians Evidence-Based Clinical Practice Guidelines. Chest. 2012;141:227S-77S

30. Wein L, Wein S, Haas SJ, et al. Pharmacologic venous thromboembolism prophylaxis in hospitalized medical patients. A metaanalysis of randomized controlled trials. Arch Intern Med. 2007; 167:1476-86

31. Kearon C, Akl EA, Comerota AJ, et al. Antithrombotic therapy for VTE disease: Antithrombotic Therapy and Prevention of Thrombosis, 9th ed: American College of Chest Physicians Evidence-Based Clinical Practice Guidelines. Chest. 2012;141: 419S-94S.

32. Antman EM, Morrow DA, McCabe CH, et al. for the ExTRACTTIMI-25 Investigators. Enoxaparin versus unfractionated heparin with fibrinolysis for ST-Elevation myocardial infarction. N Engl J Med. 2006;354:1477-88.

33. Antman EM, McCabe CH, Gurfinkel EP, et al. Enoxaparin prevents death and cardiac ischemic events in unstable angina/nonQ-Wave myocardial infarction: results of the Thrombolysis In Myocardial Infarction (TIMI) 11B Trial. Circulation. 1999;100: 1593-601.

34. Host J, Lindblad B, Bergqvist D, et al. Protamine neutralization of intravenous and subcutaneous low-molecular-weight heparin (tinzaparin, logiparin). An experimental investigation in healthy volunteers. Blood Coagul Fibrinolysis. 1994;5:795-803.

35. Van Ryn-McKenna J, Cai L, Ofosu FA, et al. Neutralization of enoxaparin-induced bleeding by protamine sulfate. Thromb Haemost. 1990;63:271-4.

36. Selleng K, Warkentin TE, Greinacher A. Heparin-induced thrombocytopenia in intensive care patients. Crit Care Med. 2007;35:1165-76.

37. Martel N, Lee J, Wells PS. Risk for heparin-induced thrombocytopenia with unfractionated and low-molecular-weight heparin thromboprophylaxis: a meta-analysis. Blood. 2005;106:2710-5.

38. Warkentin TE, Kelton JG. Temporal aspects of heparin-induced thrombocytopenia. N Engl J Med. 2001;344:1286-92.

39. Warkentin TE, Greinacher A, Koster A, Lincoff AM. Treatment and prevention of heparin-induced thrombocytopenia: American College of Chest Physicians Evidence-Based Clinical Practice Guidelines (8th Edition). Chest. 2008;133:340S-80S.

40. Buller HR, Davidson BL, Decousus H, et al. Fondaparinux or enoxaparin for the initial treatment of symptomatic deep venous thrombosis: a randomized trial. Ann Intern Med. 2004;140: 867-73.

41. The Matisse Investigators. Subcutaneous fondaparinux versus intravenous unfractionated heparin in the initial treatment of pulmonary embolism. N Engl J Med. 2003;349:1695-702.

42. Cohen AT, Davidson BL, Gallus AS, et al., for the ARTEMIS Investigators. Efficacy and safety of fondaparinux for the prevention of venous thromboembolism in older acute medical patients: randomized placebo controlled trial. BMJ. 2006;332: 325-9.
43. Agnelli G, Bergqvist D, Cohen AT, et al. Randomized clinical trial of postoperative fondaparinux versus perioperative dalteparin for prevention of venous thromboembolism in high-risk abdominal surgery. Br J Surg. 2005;92:1212-20.

44. Bauer KA, Eriksson BI, Lassen MR, et al., for the Steering Committee of the Pentasaccharide in Major Knee Surgery Study. Fondaparinux compared with enoxaparin for the prevention of venous thromboembolism after elective major knee surgery. N Engl J Med. 2001;345:1305-10.

45. Lassen MR, Bauer KA, Eriksson BI, et al., for the European Pentasaccharide Elective Surgery Study Steering Committee. Postoperative fondaparinux versus preoperative enoxaparin for prevention of venous thromboembolism in elective hip-replacement surgery: a randomised double-blind comparison. Lancet. 2002;359:1715-20.

46. Eriksson BI, Bauer KA, Lassen MR, et al., for the Steering Committee of the Pentasaccharide in Hip-Fracture Surgery Study. Fondaparinux compared with enoxaparin for the prevention of venous thromboembolism after hip-fracture surgery. N Engl $\mathrm{J}$ Med. 2001;345:1298-1304.

47. Turpie AGG, Bauer KA, Eriksson BI, et al. Fondaparinux vs enoxaparin for the prevention of venous thromboembolism in major orthopedic surgery. A meta-analysis of 4 randomized double-blind studies. Arch Intern Med. 2001;162:1833-40.

48. Eriksson BI, Lassen MR, for the PENTasaccharide in HipFRActure Surgery Plus Investigators. Duration of prophylaxis against venous thromboembolism with fondaparinux after hip fracture surgery: a multicenter, randomized, placebo-controlled, double blind study. Arch Intern Med. 2003;163:1337-42.

49. Dager WE, Dougherty JA, Nguyen PH, et al. Heparin-induced thrombocytopenia: treatment options and special considerations. Pharmacotherapy. 2007;27:564-87.

50. Smythe MA, Dager WE, Patel NM. Managing complications of anticoagulant therapy. J Pharm Pract. 2004;17:327-46.

51. Bijsterveld NR, Moons AH, Boekholdt M, et al. Ability of Recombinant Factor VIIa to reverse the anticoagulant effect of the pentasaccharide fondaparinux in healthy volunteers. Circulation. 2002;106:2550-4.

52. Di Nisio M, Middeldorp A, Buller HR. Direct thrombin inhibitors. N Engl J Med. 2005;353:1028-40.

53. Hursting MJ, Soffer J. Reducing harm associated with argatroban; practical considerations of argatroban therapy in heparininduced thrombocytopenia. Drug Saf. 2009;32:203-18.

54. Love JE, Ferrell C, Chandler W. Monitoring direct thrombin inhibitors with a plasma diluted thrombin time. Thromb Haemost. 2007;98:234-42.

55. Warkentin TE. Current agents for the treatment of patients with heparin-induced thrombocytopenia. Curr Opin Pulm Med. 2002; 8:405-12.

56. Lewis BE, Wallis DE, Hursting MJ, et al. Effects of argatroban therapy, demographic variables, and platelet count on thrombotic risks in heparin-induced thrombocytopenia. Chest. 2006;129: 1407-16.

57. Kiser TH, Fish DN. Evaluation of bivalirudin treatment for heparininduced thrombocytopenia in critically ill patients with hepatic and/ or renal dysfunction. Pharmacotherapy. 2006;26:452-60.

58. Elg M, Carlsson S, Gustafsson D. Effect of activated prothrombin complex concentrate or recombinant factor VIIa on the bleeding time and thrombus formation during anticoagulation with a direct thrombin inhibitor. Thromb Res. 2001;101:145-57.

59. - Ageno W, Gallus AS, Wittkowsky A, et al. Oral Anticoagulant Therapy: Antithrombotic Therapy and Prevention of Thrombosis, 9th ed: American College of Chest Physicians Evidence-Based Clinical Practice Guidelines. Chest. 2012;141:44S-88S. This article summarizes the unique pharmacology and pharmacodynamic properties of vitamin $K$ antagonists as well as the novel 
agents dabigatran and rivaroxaban. There is additional provided on the dosing, therapeutic monitoring, and managing reversal.

60. - Holbrook A, Schulman, Witt DM, et al. Evidence-based management of anticoagulant therapy: Antithrombotic Therapy and Prevention of Thrombosis, 9th ed: American College of Chest Physicians Evidence-Based Clinical Practice Guidelines. Chest. 2012:141;152S-184S. This article provides guidelines on the best practices with anticoagulant use. The focus is on vitamin $K$ antagonists and covers the controversial topics of therapy initiation, pharmacogenetic testing, monitoring frequency, bridging during sub-optimal anticoagulation, and drug interactions. The authors also discuss management of anticoagulant complications including management of patients that are over anticoagulated with and without bleeding.

61. Rieder MJ, Reiner AP, Gage BF, et al. Effect of VKORC1 haplotypes on transcriptional regulation and warfarin dose. N Engl J Med. 2005;352:2285-93.

62. Higashi M, Veenstra DL, Wittkowsky AK, et al. Influence of CYP2C9 genetic variants on the risk of overanticoagulation and of bleeding events during warfarin therapy. JAMA. 2002;287: $1690-8$.

63. The International Warfarin Pharmacogenetics Consortium. Estimation of the warfarin dose with clinical and pharmacogenetic data. N Engl J Med. 2009;360:753-64.

64. Crowther MA, Ginsberg JB, Kearon C, et al. A randomized trial comparing 5-mg and 10-mg warfarin loading doses. Arch Intern Med. 1999;159:46-8.

65. Kearon C, Ginsberg J, Kovacs MJ, et al., for the Extended Low Intensity Anticoagulation for Thrombo-embolism Investigators. Comparison of low-intensity warfarin therapy with conventionalintensity warfarin therapy for long-term prevention of recurrent thromboembolism. N Engl J Med. 2003;349:631-9.

66. Hylek EM, Skates SJ, Sheehan MA, Singer DE. An analysis of the lowest intensity of prophylactic anticoagulation for patients with nonrheumatic atrial fibrillation. N Engl J Med. 1996;335: $540-6$.

67. Hering D, Piper C, Bergemann R, et al. Thromboembolic and bleeding complications following St. Jude medical valve replacement: results of the German Experience With LowIntensity Anticoagulation Study. Chest. 2005;127:53-9.

68. Hurlen M, Abdelnoor M, Smith P, et al. Warfarin, aspirin, or both after myocardial infarction. N Engl J Med. 2002;347:969-74.

69. Makris M, van Veen JJ, McLean R. Warfarin anticoagulation reversal: management of the asymptomatic and bleeding patient. J Thromb Thrombolysis. 2010;29:171-81.

70. O'Donnell M, Kearon C. Perioperative management of oral anticoagulation. Cardiol Clin. 2008;26:200-309.

71. Boehringer Ingelheim. Pradaxa (dabigatran etexilate) Package Insert. http://bidocs.boehringer-ingelheim.com/BIWebAccess/View Servlet.ser?docBase=renetnt\&folderPath=/Prescribing\%20Informat ion/PIs/Pradaxa/Pradaxa.pdf (2012). Accessed 2 Jan 2013.

72. Spinler BE, Baetz SA. Dabigatran etexilate: an oral direct thrombin inhibitor for prophylaxis and treatment of thromboembolic diseases. Pharmacotherapy. 2008;28:1354-73.

73. Gulseth MP, Michaud J, Nutescu EA. Rivaroxaban: an oral direct inhibitor of factor Xa. Am J Health-Syst Pharm. 2008;65:1520-9.

74. Bayer Healthcare. Xarelto (rivaroxaban) Package Insert. http:// www.janssenmedicalinformation.com/assets/pdf/products/files/ Xarelto/pi/ENC-010330-11.pdf (2012). Accessed 2 Jan 2013.
75. Connolly SJ, Ezekowitz MD, Yusuf S, et al. Dabigatran versus warfarin in patients with atrial fibrillation. N Engl J Med. 2009; 361:1139-51.

76. Eriksson B, Borris LC, Friedman RJ, et al. Rivaroxaban versus enoxaparin for thromboprophylaxis after hip arthroplasty. N Engl J Med. 2008;358:2765-75.

77. Kakkar AK, Brenner B, Dahl OE, et al. Extended duration rivaroxaban versus short-term enoxaparin for the prevention of venous thromboembolism after total hip arthroplasty: a doubleblind, randomised controlled trial. Lancet. 2008;372(9632):31-9.

78. Lassen MR, Ageno W, Borris LC, et al. Rivaroxaban versus enoxaparin for thromboprophylaxis after total knee arthroplasty. N Engl J Med. 2008;358:2776-86.

79. Turpie A, Lassen MR, Davidson BL, et al., RECORD4 Investigators. Rivaroxaban versus enoxaparin for thromboprophylaxis after total knee arthroplasty (RECORD4): a randomised trial. Lancet 2009;373:1673-80.

80. Patel MR, Mahaffey KW, Garg J, et al. Rivaroxaban versus warfarin in nonvalvular atrial fibrillation. N Engl J Med. 2011; 365(10):883-91.

81. EINSTEIN Investigators. Oral rivaroxaban for symptomatic venous thromboembolism. N Engl J Med. 2010;363:2499-510.

82. EINSTEIN-PE Investigators. Oral rivaroxaban for the treatment of symptomatic pulmonary embolism. New Engl J Med. 2012; 366:1287-97.

83. - Rybak I, Ehle M, Buckley L, Fanikos J. Efficacy and safety of novel anticoagulants compared with established agents. Ther Adv Hematol. 2011;2:175-95. This article reviews dabigatran, rivaroxaban, and apixaban, focusing on the results from major clinical trials for venous thromboembolism (VTE) prophylaxis in orthopedic surgery patients, VTE treatment, secondary prevention of cardiovascular events after myocardial infarction, and stroke prophylaxis in nonvalvular atrial fibrillation. It also highlights agents currently under development that will likely impact future practice.

84. Granger C, Alexander J, McMurray L, et al. Apixaban versus warfarin in patients with atrial fibrillation. N Engl J Med. 2011; 365:981-92.

85. Miyares MA, Davis K. Newer anticoagulants: a review of laboratory monitoring options and reversal agents in the hemorrhagic patient. Am J Health-Syst Pharm. 2012;69:1473-84.

86. • Eerenberg ES, Kamphuisen PW, Sijpkens MK, et al. Reversal of rivaroxaban and dabigatran by prothrombin complex concentrate. A randomized, placebo-controlled, crossover study in healthy subjects. Circulation. 2011;124:1573-9. This randomized, double-blind, placebo-controlled crossover trial studied the reversal effect of prothrombin complex concentrate (PCC) on rivaroxaban $20 \mathrm{mg}$ twice daily and dabigatran $150 \mathrm{mg}$ twice daily in healthy male volunteers. After administration of PCC 50 units $/ k g$, prothrombin time and endogenous prothrombin time normalized in rivaroxaban patients. However, PCC had no effect on activated partial thromboplastin time, endogenous thrombin potential lag time, ecarin clotting time, or thrombin time in dabigatran patients. The authors caution that the clinical significance of these findings should be studied further.

87. Marlu R, Hodaj E, Paris A, et al. Effect of non-specific reversal agents on anticoagulant activity of dabigatran and rivaroxaban. A randomized cross over ex vivo study in health volunteers. Thromb Haemost. 2012;108:217-24. 